\title{
Experimental Investigation and Numerical Modeling for Stability of Thin Corrugated Webs in Steel Plates Girders
}

\author{
Haitham H Muteb ${ }^{1}$, Dhafer M Hasan ${ }^{2}$ \\ ${ }^{1}$ College of Engineering, University of Babylon (UoB), PO box 247, Hilla, Iraq \\ ${ }^{2}$ College of Engineering, University of Karbala, Karbala, Iraq, a Ph.D. student at the University of \\ Babylon, Hilla, Iraq.
}

\begin{abstract}
.
The capacity of steel girders and composite girders generally depends on their web stability. Therefore, webs could be reinforced by stiffeners or a corrugated shape could be used to increase their stability. Of the two previous techniques, the corrugated shape was used in a new pattern similar to the transverse stiffeners, which increases the flexural rigidity of the plate. Then the shear stability of the web is stronger. In the present study, the stability of thin-walled corrugated webs is investigated experimentally and numerically. In the experimental part, five steel plate beams and three composite beams were made using a new corrugated fabric pattern and tested under static load. However, the test results were compared to another previous test of flat web beams. The results showed that the girders with corrugated shape would be had different behavior than the girders with a flat web. Also, the composite girder with the deck slab of UHPC revealed that the deck slab contributed with the web to resist the shear stress. Therefore, the corrugated technique showed that action could be used as an alternative to reinforced the web, especially in the composite girders. Because of this technique increased the shear strength capacity by about $44 \%$ than flat web composite girders. All the composite failed due to the web buckled without crushing or cracking the UHPC deck. Where the normalize, shear was reached to 0.7 of the yield shear stress when used a corrugated web. The finite element analysis by the ABAQUS software program was performed, which shows a reasonable comparison between results.
\end{abstract}

Keywords: steel plate girder, corrugated web, elastic shear buckling, post-buckling, ultra-high-performance concrete.

\section{Introduction}

Nowadays, traffic has grown so that this growth needs structures that must do in a modern way, as well as, many intersections have become overpass bridges. The bridges of the highway or expressway always have long spans. In buildings, for architectural purposes, the long spans become a favorite feature. Therefore, structural constriction should be lightweight, high strength, and ductile. All previous features are essential properties that must examine under 


\section{$2^{\text {nd }}$ International Conference on Research in ENGINEERING and TECHNOLOGY \\ 25_27 September, 2020 \\ BERLIN, Germany}

static load. The composite profile can be used in the bridges and in building constructions to support the bridge deck, building floors, or roofs.

The composite section is widely adopted for bridgework and is represented practically universal for plate girder or beam bridges with reinforced concrete decks. Alternatively, the plate girderprops the concrete deck during construction and continuously for service live and reduce deflection [1].

Plate girder includes local instability since it is deeper and has a thin web. Conventionally, intermediate stiffeners web is used to developed tension field action, which increases the capability of the member to resists shear load. Additional stiffeners maybe use at the point of concentrated load or bearings points to prevents compressive force applied on the web directly or crippling [2].

The aspect ratio of the depth to length is about $1 / 6$ to $1 / 15$, which means the plate girder has a high depth. The high depth of the web, according to thickness, should be made a week resistance of the shear strength [2]. The weakness phenomena of the web reinforce by using intermediate stiffeners. In the present study, adopted a plate girder reinforced its web by corrugated plate to enhance stability, this technique used from three decades. The corrugated plate properties plate matches the features of the orthotropic plate. The orthotropic plate, which knowns as anisotropic plate, these materials have different elastic properties in two orthotropic directions [3]. The variations in the properties are changed. The corrugated plate is one of the applications of the orthotropic plate which has flexural rigidity along one direction more than the other direction. Therefore, they use a corrugated plate instead of a flat plate in civil applications such as composite slab and web of girders.

Built-up I-section steel plate girders are used as metal building system members because they can be precisely optimized for the least weight. They are also used commonly in longer-span bridges and as building girders[4]. In most plate girders, the shearing stress on the web is relatively lower than the normal stress in flanges. Therefore, to obtain a high strength to weight ratio, it is common to choose deep girders or/and thin web. The designers must balance between the length of the span and the cost. The length of the span will be increased the flexural stress and shear stress. The flexural strength increases by increases the distance between flanges. Therefore, the webs become slenderer. Thus, the web of the girders becomes unstable [5].

To avoid web buckling, reinforced the web by intermediate stiffeners, which increase the critical shear buckling stress [6]. Sometimes, unstiffened webs used when they are less expensive than stiffened webs or when stiffeners are aesthetically unacceptable [4].

The corrugated web may use as an alternative to transverse stiffeners on the web. That technology increases the shear strength capacity of the web [7]. There are many types of corrugation is possible, trapezoidal, and sinusoidal [8]. However, the corrugation web commonly used in high-way bridges and the building structure.

The corrugated web failed thereby instability, so the shear buckling failure mode is classified into three types; Local buckling occurs in the single fold, global buckling which extends in multiple folds, with buckles extending over the whole depth of the web, and interactive buckling 


\section{$2^{\text {nd }}$ International Conference on Research in ENGINEERING and TECHNOLOGY \\ 25_27 September, 2020 \\ BERLIN, Germany}

which occurs due to interaction between local and global bucking [7]. The shear strength of corrugated web girders depends on numerous factors such as; web depth, thickness, corrugation geometry, and materials. Global buckling may be predominant for fine corrugation, while local buckling appeared in course corrugation [8].

The main advantages are that the corrugated web could be 30 to 60 percent lighter than the flat webs girder, which has the same capacity of shear strength. Thus, larger spans could conduct with less weight. Moreover, the corrugation appearance of the webs improves the aesthetics of the structure [8]. In the corrugated web, the critical shear buckling stressed are increased. Also, the corrugation technique increases the out-of-plain stiffness of the web, and eliminate the use of the vertical stiffeners.

In the flexural failure, the corrugated web reduces the flange vertical buckling significantly. Finally, the corrugated web is weak to resist direct stress due to the bending moment. Therefore, the web does not resist the stress of bending moment. The bending stress by flange only, so no need for an interaction diagram when the calculated shear strength. The inelastic buckling occurred when local or global, elastic buckling exceed $80 \%$ of yield stress, $\tau_{y}$, therefore, Elgaaly 1996 [9] proposed a reduction factor equaled 0.8 to calculate inelastic buckling.

The web stability increased in several ways; namely, reinforced web by used transverse or longitudinal stiffeners was mentioned by Chen et al. [6] and Bergfelt et al. [10]. Likewise, a corrugated technique that has been used to increase the stability of the web was revealed by Abass et al.[11]. The corrugation web affected by several factors such as welded pattern length was adopted by Sharman and Fisher[12], fold configuration was investigated by Dahlen and Krona [13], web slenderness was studied by Elgaaly, and Hamilton [9], and hight of the corrugated was examined by Gil et al.[14]. Those researches revealed that the corrugated web could be used to increase the stability of the web. Therefore, a trapezoidal corrugation technique suggested using instead of the transverse stiffeners in the present study. So this technique proposed to achieve in a unique new pattern of corrugated, which simulated the transverse stiffeners.

The composite girders have a capacity greater than plate girders, so this study concern with investigating the new pattern of corrugated and compare with corresponded flat web composite girders and the length to depth ratio. The previous researches showed the composite girders effected by the slenderness web remarked by Baskar and Shanwuam[15]. The shear connector is an important factor effect on the behavior of the composite girders, which revealed by Allison et al. [16] and Rebarts and Al-amery[17]. The thickness of the slab influences the shear strength capacity of the composite girders, which approved by Yoo and Choo [18].

This study aims to use the corrugated technique to reinforce the web and increased web stability, where the corrugated pattern proposed as an alternative to intermediate stiffeners. Therefore, the web folded as a trapezoidal shape, and these folded distributed longitudinally at a constant interval. The trapezoidal folds formed in sequences direction for each side.

\section{Experimental Program}




\section{$2^{\text {nd }}$ International Conference on Research in ENGINEERING}

and TECHNOLOGY

\section{5_27 September, 2020}

The present paper investigated the behavior and shear stability of the plate girders and composite girders with the corrugated web.

\subsection{Plate Girders}

Five plate girders with corrugated web were tested. The corrugated plate girders were remarked as; "'CWxx", where the first part ' $\mathrm{CW}$ ' indicates the corrugated web, while the second part " $\mathrm{xx}$ " represented the sequence number of the girders. The first parameter has conducted the location of the neutral axis effects in the behavior of the girder. Therefore, the web may buckle due to a combination of shear stress and compressive bending stress, as explained in Figure 1. The second parameter has investigated the effect of length to depth ratio. Three values of length to depth ratio L/D were conducted of 4.7, 7.0, and 10.5, as listed in Table 1.
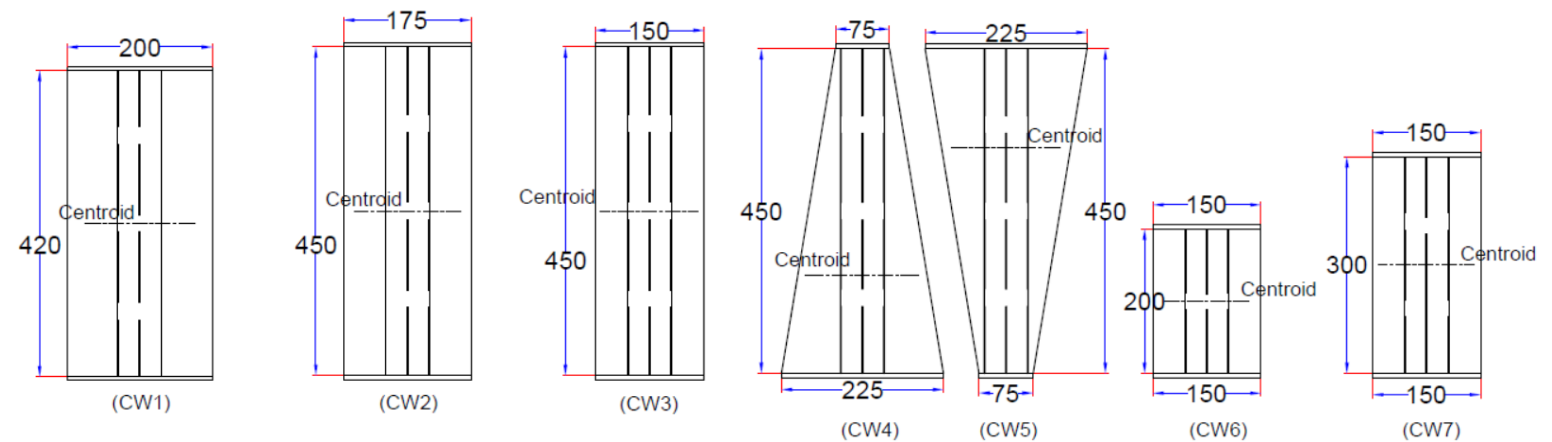

Figure 1: Cross-section details of CW plate girders.

The shape of the corrugated was implemented as a trapezoidal shape, which commonly used. With new mode of corrugation was suggested, as explained in Figure 2, which used as an alternative technique to transverse stiffeners. This new pattern configured of four trapezoidal were folded for one panel of the web, where every two folds formed on one side while the two others were folded on the opposite side and distributed at a constant distance of $260 \mathrm{~mm}$. Therefore, that pattern of corrugated is simulated to use one side intermediate transverse stiffeners in sequence mode. This proposed corrugation remains part of the web panel as a flat web between two adjacent folds — that sub-panel, which had a width of $185.5 \mathrm{~mm}$. 
25_27 September, 2020

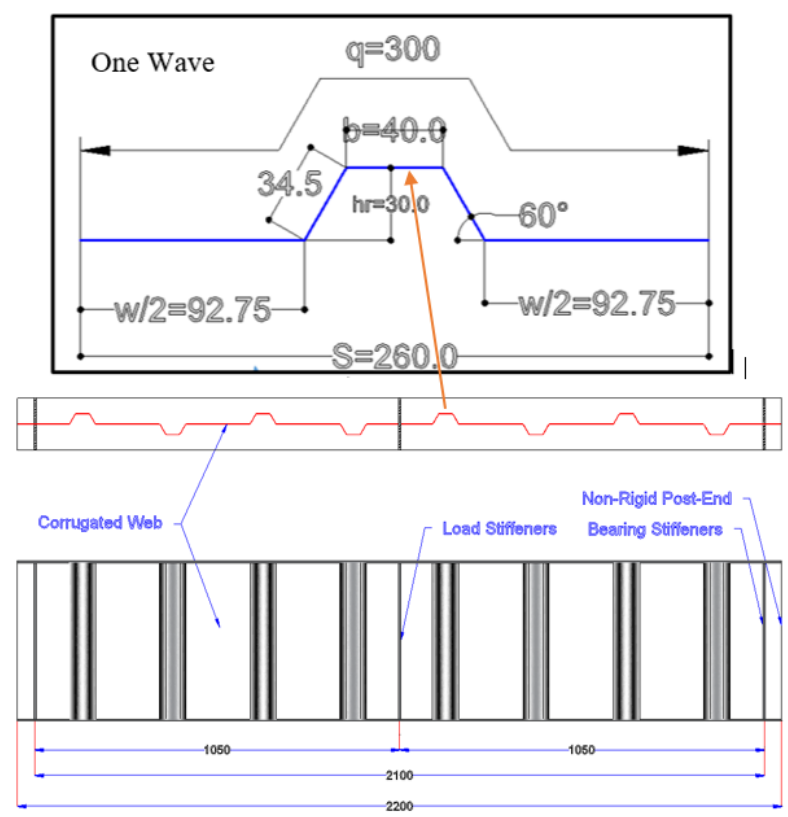

Figure 2: Corrugation shape.

Table 1: Details of CW plate Girders.

\begin{tabular}{|c|c|c|c|c|c|c|c|c|}
\hline $\begin{array}{c}\text { Plate } \\
\text { girder }\end{array}$ & $\begin{array}{c}\text { Top } \\
\text { Flange } \\
\text { width, } \mathrm{b}_{f t}\end{array}$ & $\begin{array}{c}\text { Flange } \\
\text { Thick. } \\
\mathrm{t}_{f t}\end{array}$ & $\begin{array}{c}\text { Bottom } \\
\text { Flange width, } \\
\mathrm{b}_{f b}\end{array}$ & $\begin{array}{c}\text { Flange } \\
\text { Thick. } \mathrm{t}_{f b}\end{array}$ & $\begin{array}{c}\text { Web } \\
\text { Depth, D }\end{array}$ & $\begin{array}{c}\text { Web } \\
\text { thick., } \\
\mathrm{t}_{\mathrm{w}}\end{array}$ & N.A. & L/D \\
\hline FW3 & 150 & 5.8 & 150 & 5.8 & 450 & 1.2 & mid & 4. \\
\hline FW4 & 75 & 5.8 & 225 & 5.8 & 450 & 1.2 & Bot. & 4.7 \\
\hline FW5 & 225 & 5.8 & 75 & 5.8 & 450 & 1.2 & top & 4.7 \\
\hline FW6 & 150 & 5.8 & 150 & 5.8 & 200 & 1.2 & mid & 10.5 \\
\hline FW7 & 150 & 5.8 & 150 & 5.8 & 300 & 1.2 & mid & 7.0 \\
\hline
\end{tabular}

\subsection{Composite Girders}

The three composite girders have comprised of the corrugated web and UHPC of the deck. The designation of the composite girders with the corrugated web was 'C.CWxx"'. Where, the first part, 'C.' ' refers to the composite section, while the second part ' $\mathrm{CW}$ '" refers to the corrugated web, and the third part " $x x$ " refers to the sequence number of the girders, as briefed in Table 2. Broadly, the parameter was studied here was the effect of the length to depth ratio L/D, as explained in Figure 3. However, this study investigated the influences of the using deck slab, when compared with plate girders without composite action (deck slab).

Table 2: Details of The Composite CW Girders.

\begin{tabular}{|c|c|c|c|c|c|c|c|c|}
\hline \multirow{2}{*}{$\begin{array}{c}\text { Composi } \\
\begin{array}{c}\text { te } \\
\text { Girders }\end{array}\end{array}$} & $\begin{array}{c}\text { Plate } \\
\text { Girder }\end{array}$ & $\begin{array}{c}\text { Web } \\
\text { Depth } \\
\text { D mm }\end{array}$ & $\begin{array}{c}\text { Web } \\
\text { thick. } \\
\mathrm{t}_{\mathrm{w}, \mathrm{mm}}\end{array}$ & L/D, & $\begin{array}{c}\text { Thick. } \\
\mathrm{mm}\end{array}$ & $\begin{array}{c}\text { width, } \\
\mathrm{mm}\end{array}$ & $\begin{array}{c}\text { Haunch } \\
\text { thick. } \mathrm{mm}\end{array}$ & $\begin{array}{c}\text { width, } \\
\mathrm{mm}\end{array}$ \\
\hline C.CW8 & CW6 & 200 & 1.2 & 10.5 & 34 & 400 & 15 & 150 \\
\hline
\end{tabular}




\begin{tabular}{|c|c|c|c|c|c|c|c|c|}
\hline C.CW9 & CW3 & 450 & 1.2 & 4.67 & 34 & 400 & 15 & 150 \\
\hline C.CW10 & CW7 & 300 & 1.2 & 7.5 & 34 & 400 & 15 & 150 \\
\hline
\end{tabular}

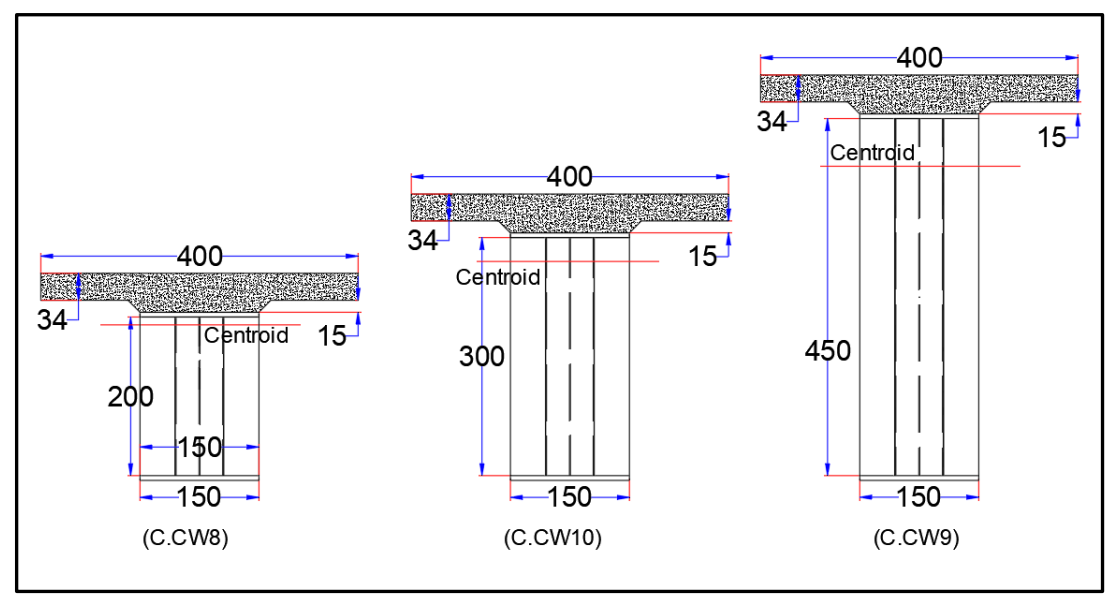

Figure 3: Composite CW girders Details.

\subsection{Concrete and deck slab}

The deck slab was manufactured from UHPC without the main reinforced concrete. The concrete ingredients were; Portland cement type R42, fine aggregate passes from sieve size of 600-micrometer, and micro silica fume mixed with superplasticizer and water and then add steel fiber of $4.5 \%$ content. The deck cast in the workshop, and after setting concrete cured by immersion in hot bathwater at $60^{\circ} \mathrm{C}$. Therefore, the deck slab represented as precast concrete, so it prepared and then connected to steel plate girders.

The thickness of the slab was suggested by $35 \mathrm{~mm}$. While, at the mid-width concrete depth enlarged the thickness from $35 \mathrm{~mm}$ to $50 \mathrm{~mm}$, that called a haunch with a height of $15 \mathrm{~mm}$ and width of 150mm, as shown in Figure 4. The haunch provides a suitable height for studs and its head to embed inside the concrete and increases the shear area of the connectors. Deck width was suggested equal to $400 \mathrm{~mm}$, which is a reasonable value, and within effective width requirements [3].

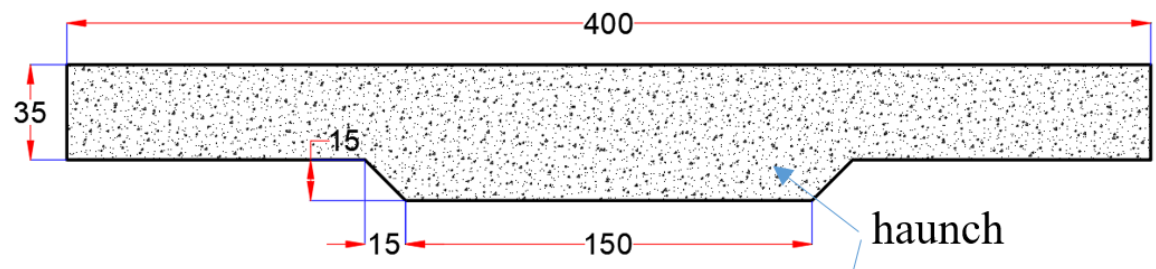

Figure 4: Deck slab details.

\subsection{Shear connectors}

The connector studs were used with a headed diameter of $12 \mathrm{~mm}$ and a length of $75 \mathrm{~mm}$. These studs were distributed along the flange as a pair (i. e., two studs at each row). However, the studs were interred through the holes, which ware prepared previously, inside the concrete. The 


\section{$2^{\text {nd }}$ International Conference on Research in ENGINEERING}

and TECHNOLOGY

\section{5_27 September, 2020}

studs tightened by used micrometer adjustable torque wrench. All nets tightened until the torsion moment equaled to $(140 \mathrm{kN}$.m). The pair of studs distributed at each of $175 \mathrm{~mm}$ along the span, in a longitudinal direction. In other words, there were twelve pairs of the studs in each composite beam, as illustrated in Figure 5. The distance between studs in the same raw (i.e., in the transverse direction) was $70 \mathrm{~mm}$. The stud properties and distributed distance have been obtained from the previous push-out test.

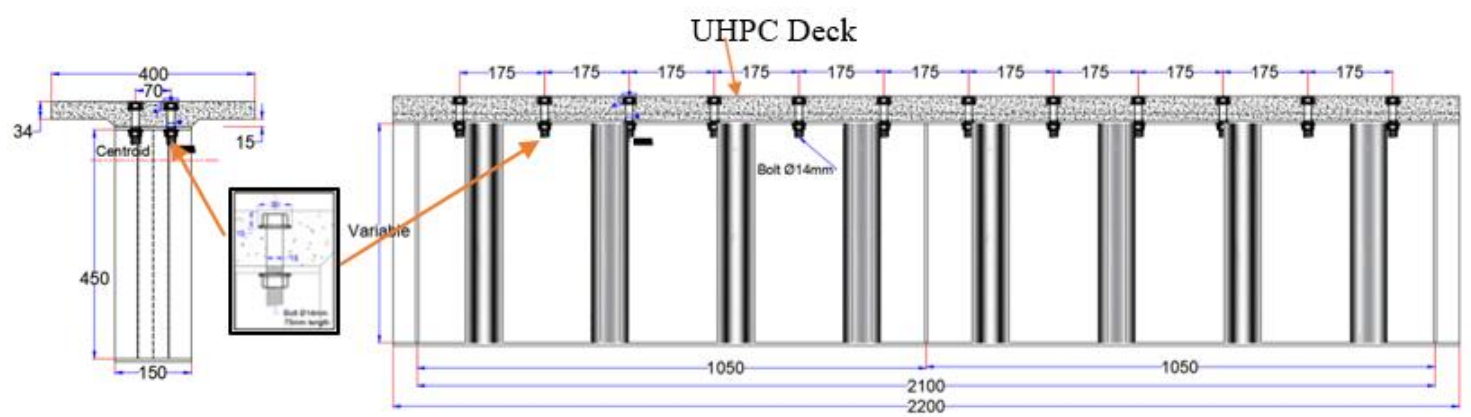

Figure 5: Composite Girders and Shear Connectors Details.

Four linear variation distance transducers LVDT's were used. Two of them are measured the vertical deflection at the mid-span and at a distance of 1/8 of effective length from mid-span. The two remains LVDT's sensors were used to measure the lateral displacement, which is perpendicular to the longitudinal axis in the top and bottom, as shown in Figure 6. The fourth LVDT, which measured the horizontal top lateral deformation, was translated to the end of the composite section to measure the relative slip value between concrete and steel through the testing of the composite section.

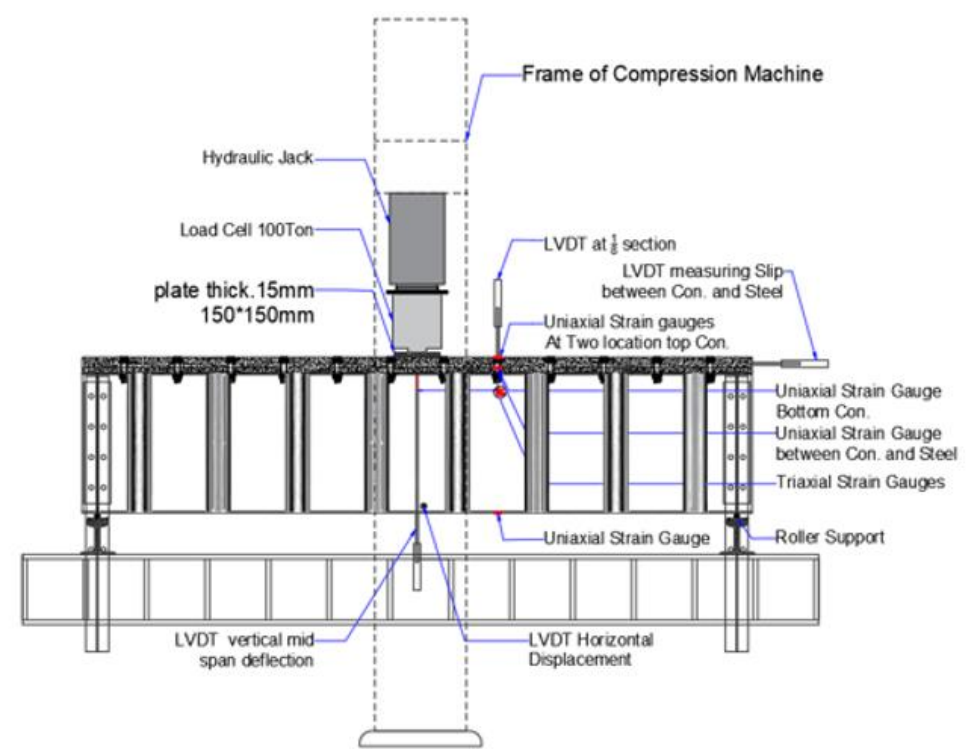

Figure 6: Test Set up.

\section{Results and Discussions}




\section{$2^{\text {nd }}$ International Conference on Research in ENGINEERING and TECHNOLOGY BERLIN, Germany \\ 25_27 September, 2020}

All girders tested under static load until failure by compression machine of 100-ton capacity. the girders supported laterally at ends to prevent torsional buckling occurred.

\subsection{The corrugated web plate girders}

The failure was occurred due to the sheer elastic buckling of the corrugated web. Generally, in the corrugated web girders, the sheer instability buckling classified into three types according to the pattern of buckled appearing on the corrugated web; The local buckling is controlled by the larger width $(w)$ to web thickness $\left(t_{w}\right)$ ratio for a sub-panel. In this case, the corrugated web acted as a series of flat sub-panels, which connected at each edge vertically and with flange horizontally. Thus the elastic local buckling stress can be calculated by classical plate theory[19], [20], [7]. The second type of failure of the corrugated web girders is the global elastic buckling. The diagonal buckling extended through whole the depth of the web as well as passes through one or more of adjacent folds. The global elastic buckling expressed like an orthotropic plate, which is proposed by Easley [21]. The third mode of failure is an interaction of the two previous types of failure was described by Elgaaly 1995[9]. The shear stress developed around each sub-panel as local effects, as well as the shear stress developed around the whole corrugated panel as global effects. Therefore, the failure occurred due to these two effects called the interaction buckling. The interaction stress $\tau_{c r, I}$, depends on the elastic stress of local buckling $\boldsymbol{\tau}_{c r, L}$, and elastic stress of global buckling $\boldsymbol{\tau}_{c r, \boldsymbol{G}}$.

\subsection{Modified the Mathematical calculating of CWG}

The conventional shear elastic buckling equations of the corrugated web girders may be inapplicable because the corrugated folds distributed in a new pattern. That means the web panel is corrugated partially, and the axis of symmetry lies in the ends of folds. The characteristic of the new pattern adopted here is different than conventional trapezoidal corrugated. Therefore, conventional expressions need to modify. These equations were divided into two parts; the first part is the coefficient of elastic buckling, and the second part matches the Euler hyperbola. The elastic buckling coefficient sets to consist of all variables, while the second part has metrical properties and the slenderness ratio of the web. Therefore, the elastic local buckling equation was modified to become, as follows;

$$
\tau_{c r, L}=\breve{k}_{L} \frac{\pi^{2} E}{12\left(1-v^{2}\right)}\left(\frac{t_{w}}{h_{w}}\right)^{2}
$$

While the $\breve{\boldsymbol{k}}_{\boldsymbol{L}}$ represented the modified coefficient of the boundary conditions and aspect ratio of the panel for local elastic buckling, which modified, as the following expression;

$$
\breve{k}_{L}=\frac{q}{s}\left[5.34\left(\frac{h_{w}}{W}\right)^{2}+4\right]
$$

The vertical support of the sub-panel was reduced about q/S because of the flexural rigidity legrigidity when a plate folds.

Since the global elastic buckling depends on the corrugated shape, therefore, the axis of symmetric for a new pattern is different than a conventional trapezoidal corrugated shape. Thereby, the axis of symmetric lying in the ends of the folds. Therefore, the moment of inertia around the axis of symmetric, which is being strong around the $\mathrm{x}$-axis, and was calculated, as follows; 


\section{$2^{\text {nd }}$ International Conference on Research in ENGINEERING} and TECHNOLOGY

\section{5_27 September, 2020}

$$
\check{I}_{x}=0.28 *\left[\left(b \cdot t_{w} \cdot h_{r}^{2}+\frac{h_{r}^{3}}{6 \sin \alpha}\right) / q\right]
$$

Where $\breve{I}_{x}$; is the moment of inertia for corrugated fold around the X-axis per uncoiled length, q. However, the value of 0.28 represented the ratio of the corrugated length to the total length of the panel. The corrugated length for one-fold equall to $(40+17.32 * 2)$, while for four-fold becomes $298.56 \mathrm{~mm}$, and the length of the panel was $1050 \mathrm{~mm}$.

The global elastic buckling was proposed to modify, as follows;

$$
\tau_{c r, G}=\breve{k}_{G} \frac{\pi^{2} E}{12\left(1-v^{2}\right)}\left(\frac{t_{w}}{h_{w}}\right)^{2}
$$

While the $\check{\boldsymbol{k}}_{\boldsymbol{G}}$ represented the modified coefficient of the boundary conditions and aspect ratio of the panel which calculated, as the following expression;

$$
\breve{k}_{G}=\frac{12 \times 31.6}{\pi^{2} t_{w}{ }^{3}}\left[\frac{q}{s} \times\left(\check{I}_{x} \times t_{w}^{3}\right)^{3}\right]^{0.25}
$$

Where; $\breve{\boldsymbol{k}}_{\boldsymbol{G}}$, is the coefficient of the global elastic buckling, which is a function of the corrugated shape and moment of inertia about a strong axis.

The interaction elastic buckling is an essential formula to calculate the shear strength of the corrugated web girders. Therefore, the interaction elastic buckling was simplest, as the following expression;

$$
\tau_{c r, I}=\breve{k}_{I} \frac{\pi^{2} E}{12\left(1-v^{2}\right)}\left(\frac{t_{w}}{h_{w}}\right)^{2}
$$

Where; $\check{\boldsymbol{k}}_{\boldsymbol{I}}$, is the modified coefficient of the interaction elastic buckling, which is a function of support conditions, aspect ratio, the corrugated shape, and moment of inertia about a strong axis. This coefficient is computed, as follows;

$$
\check{k}_{I}=\frac{\bar{k}_{L} \times \bar{k}_{G}}{\sqrt{\bar{k}_{L}{ }^{2}+\bar{k}_{G}{ }^{2}}}
$$

The interaction equation is equaled to one unite for yield stress as a maximum value without elastic buckling where the slenderness parameter, $\lambda_{\mathrm{s}}$ is 0.6 , was remarked Moon et al. [22]. Also, the non-corrugation shape covered only the inelastic buckling occurred in 0.8 of yield stress was used by Elgaaly et al. [11]. when the inelastic buckling corresponded to the slenderness parameter, $\lambda \mathrm{s}$, which equal to 1.58 , was considered by Moon et al. [22]. The inelastic limit slenderness is different according to $\mathrm{k}_{\mathrm{I}}$ value, as listed in The experimental results have an increment ratio than the calculated results of about 1.02 to 1.14.

Table 3. Therefore, the variation in the inelastic zone assumes it varies linearly, so the general interaction elastic and inelastic buckling equation summarized in the simplest way these actions have been adopted by Moon et al.[22] and Gil et al. [14] as;

$$
\frac{\tau_{c r, L} \text { ine }}{\tau_{y}}=1 \text { for } \lambda_{s}<0.6
$$




\section{$2^{\text {nd }}$ International Conference on Research in ENGINEERING} and TECHNOLOGY

25_27 September, 2020

$$
\begin{aligned}
& \frac{\tau_{c r, L}^{\text {ine }}}{\tau_{y}}=1.441-0.735 \lambda_{s} \text { for } 0.6 \leq \lambda_{s}<1.58 \\
& \frac{\tau_{c r, L}{ }^{\text {el }}}{\tau_{y}}=\frac{0.7}{\lambda_{s}^{2}} \text { for } \lambda_{s} \geq 1.58
\end{aligned}
$$

Where; $\lambda \mathrm{s}$ is the slenderness parameter and in the present study is calculated as follows;

$$
\lambda_{s}=0.815 \sqrt{\frac{F y}{k_{I} E}} \times\left(\frac{h_{w}}{t_{w}}\right)
$$

The factors that influence the global elastic buckling expression are the corrugated shape, depth of the web, and thickness of the web. In the present study, the configuration shape of folds is constant, but the distance between folds was varied. The three elastic coefficients $\breve{\boldsymbol{k}}_{\boldsymbol{L}}, \check{\boldsymbol{k}}_{\boldsymbol{G}}$, and $\check{\boldsymbol{k}}_{\boldsymbol{I}}$ according to equations 2,5 , and 7 , as well as the stress of the elastic buckling of three types; local $\tau_{\mathrm{cr}, \mathbf{L}}$, global $\tau_{\mathrm{cr}, \mathbf{G}}$, and interaction $\tau_{\mathrm{cr}, \mathrm{I}}$, are listed in The experimental results have an increment ratio than the calculated results of about 1.02 to 1.14 .

Table 3 by using modified equations of 1,4 , and 6 . The calculating results according to the modified equation adopted here showed that the interaction stress of the elastic buckling is weaker stress when compared with local elastic buckling or global elastic buckling. The experimental results have an increment ratio than the calculated results of about 1.02 to 1.14.

Table 3: Calculating buckling stress and testing Results.

\begin{tabular}{|c|c|c|c|c|c|c|c|c|c|}
\hline girders & $\check{\mathrm{k}}_{\mathrm{L}}$ & $\check{\mathrm{k}}_{\mathrm{G}}$ & $\check{\mathrm{k}}_{\mathrm{I}}$ & $\begin{array}{c}\tau_{\mathrm{cr}, \mathrm{L}}, \\
\mathrm{MPa}\end{array}$ & $\begin{array}{c}\tau_{\mathrm{cr}, \mathrm{G},} \\
\mathrm{MPa}\end{array}$ & $\begin{array}{c}\tau_{\mathrm{cr}, \mathrm{I},} \\
\mathrm{MPa}\end{array}$ & $\begin{array}{c}\text { Load } \\
\mathrm{kN}\end{array}$ & $\begin{array}{c}\tau_{\text {exp. }} \\
\mathrm{MPa}\end{array}$ & $\begin{array}{c}\text { Increment } \\
\text { ratio } \\
\tau_{\text {exp. }} / \tau_{\mathrm{cr}, \mathrm{I}}\end{array}$ \\
\hline CW3 & 31.28 & 42.76 & 25.24 & 40.20 & 55 & 32.45 & 40.00 & 37 & 1.14 \\
\hline CW4 & 31.28 & 42.76 & 25.24 & 40.20 & 55 & 32.45 & 37.50 & 35 & 1.07 \\
\hline CW5 & 31.28 & 42.76 & 25.24 & 40.20 & 55 & 32.45 & 40.00 & 37 & 1.14 \\
\hline CW6 & 9.01 & 42.76 & 8.82 & 58.64 & 192 & 57.38 & 28.2 & 63 & 1.02 \\
\hline CW7 & 15.86 & 42.76 & 14.87 & 45.88 & 124 & 43.01 & 31.61 & 44 & 1.02 \\
\hline
\end{tabular}

The elastic and inelastic interaction equation is drawing in Figure 7, according to equations 1, 4 , and 6, and then plotted the experimental test results for comparison. The competition of these equations shows a good convergence with experimental results. 


\section{$2^{\text {nd }}$ International Conference on Research in ENGINEERING and TECHNOLOGY \\ 25_27 September, 2020 \\ BERLIN, Germany}

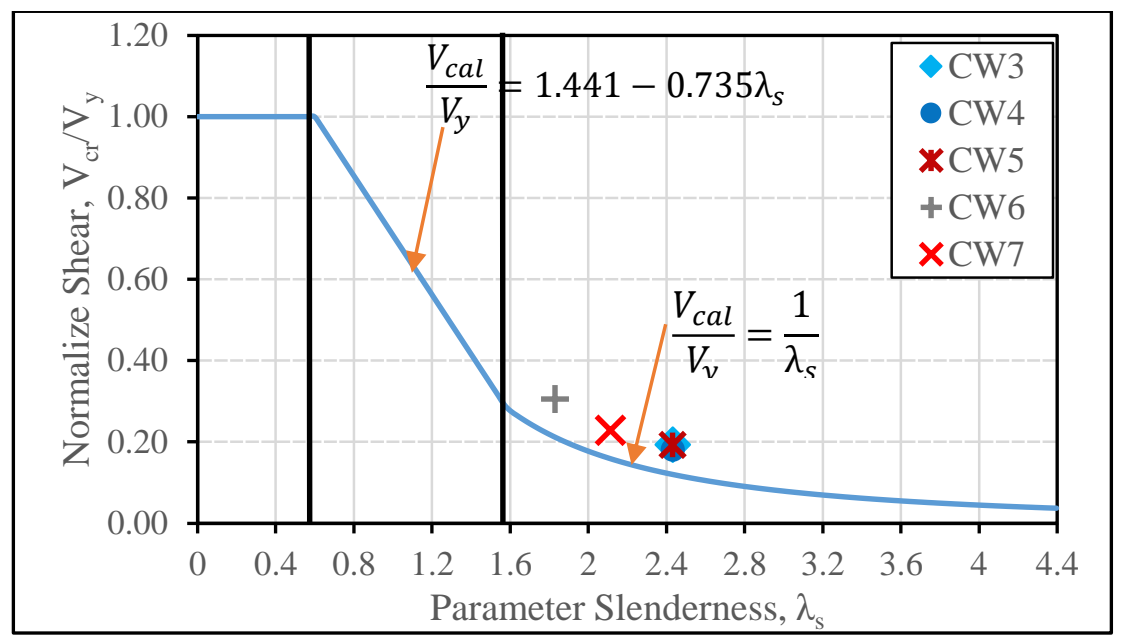

Figure 7: Elastic Buckling Stress calculated by modified expression.

All corrugated web girders were failed due to web buckling in the sub-panel and extended to the corner of the corrugated folds, which is known as interaction elastic buckling, as explained in Figure 8. Generally, the elastic buckling is a conservative failure with a very slight margin of post-buckling because of the accordion shape. Therefore, the corrugation web has a weak resistance to diagonal tensile stress.
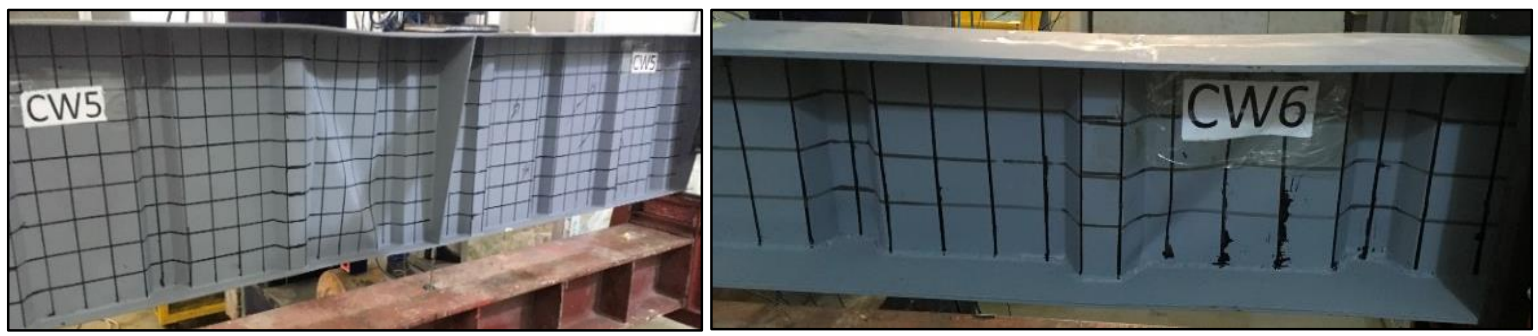

Figure 8: Mode of failure appeared at the plate girders

The relationship of normalizing shear and deflection of the girders with different location of the neutral axis showed that the behavior is slightly different, especially in the initial load, as explained in Figure 9. The critical shear stress of girder CW3 was less than girder CW7, while girder CW6 had higher shear stress, as illustrated in Figure 10. That means the shear stress capacity increases when the L/D ratio increase because of the web slenderness decreases.

The results of the girders were compared with the flat web (part 1 of the present study), as explained in Figure 11, which showed that the corrugated technique increases the shear elastic buckling capacity of the girders.

\subsection{Composite girders results}

The out of plane deformation appeared on the web for all composite girders without crushing or cracking concrete, as observed in Figure 12. The normalize shear and normalize deflection were plotted in Figure 13 for the composite girders with the corrugated web. These girders are C.CW8 has an L/D ratio of 10.5, C.CW10 has an L/D ratio of 7.0, and C.CW9 has an L/D ratio of 4.7. Girder C.FW9 failed earlier than girder C.FW10, while girder C.FW8 failed later. The 


\section{5_27 September, 2020}

normalize shear stress was $0.72,0.65$, and 0.56 for girders C.CW8, C.CW10, and C.CW9, respectively. These results revealed that the corrugated web and deck of UHPC increases the shear strength capacity of the composite girders.

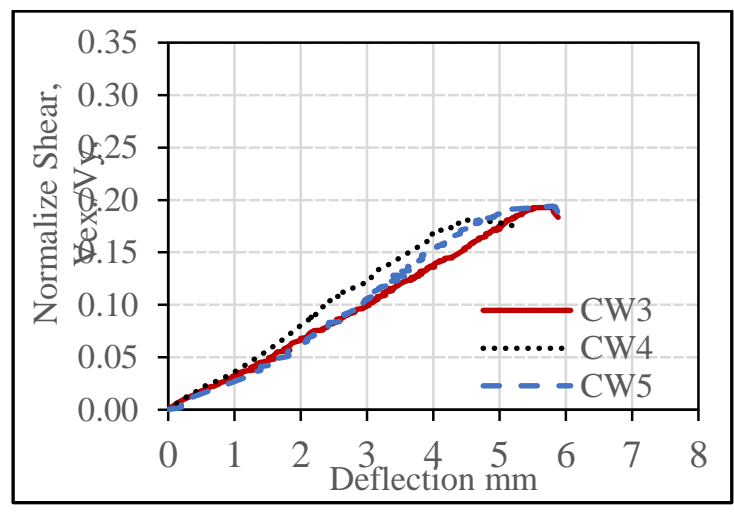

Figure 9: Normalize Shear Vs., Deflection of Different N.A.
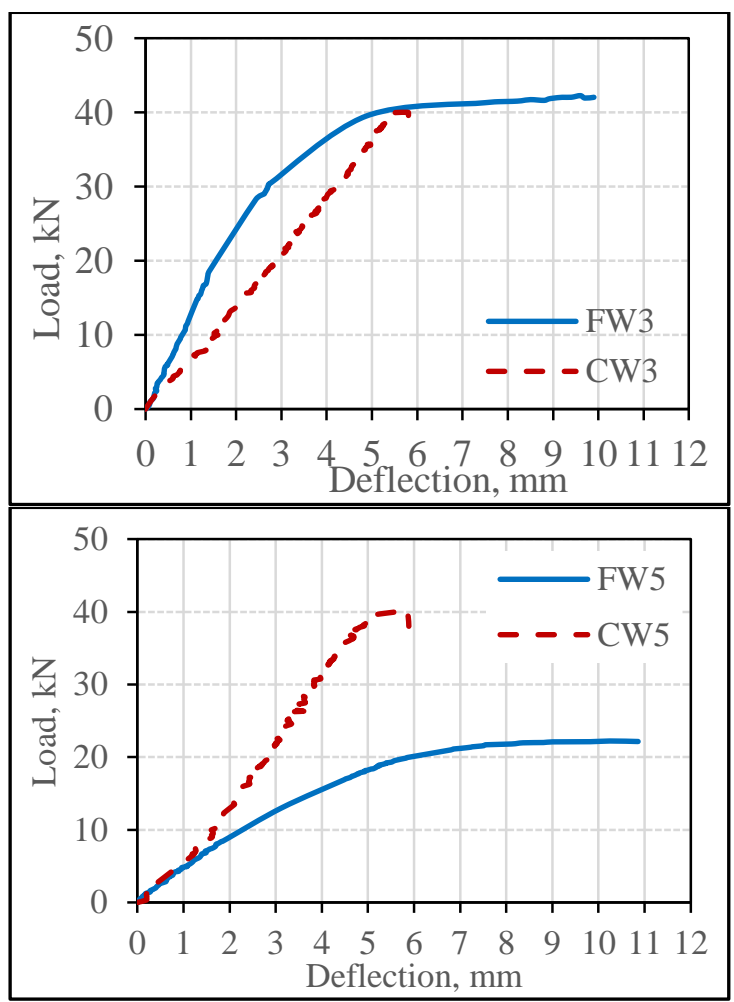

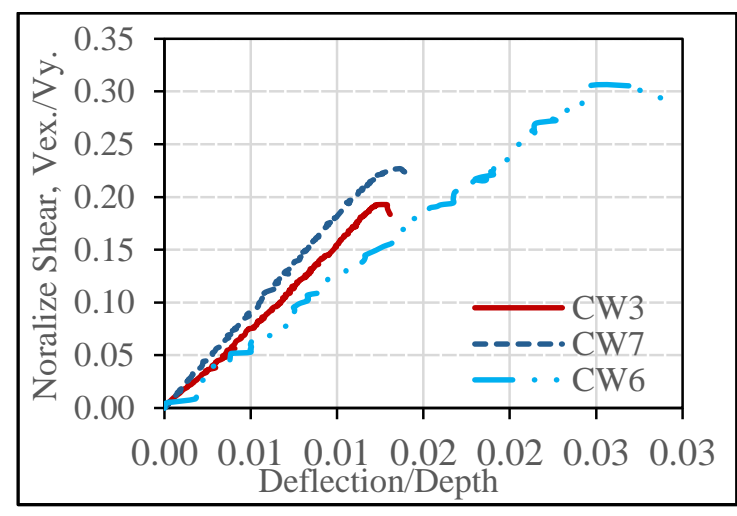

Figure 10: Normalize Shear Vs. Normalize the Defection of different L/D.
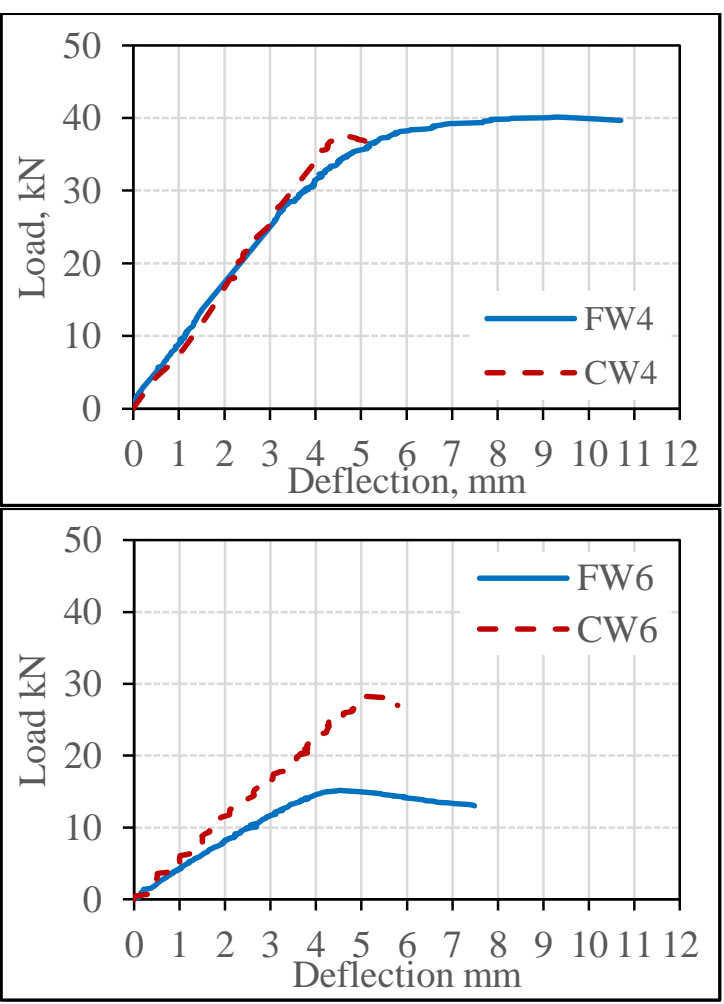


\section{$2^{\text {nd }}$ International Conference on Research in ENGINEERING}

and TECHNOLOGY

\section{5_27 September, 2020}

\section{BERLIN, Germany}

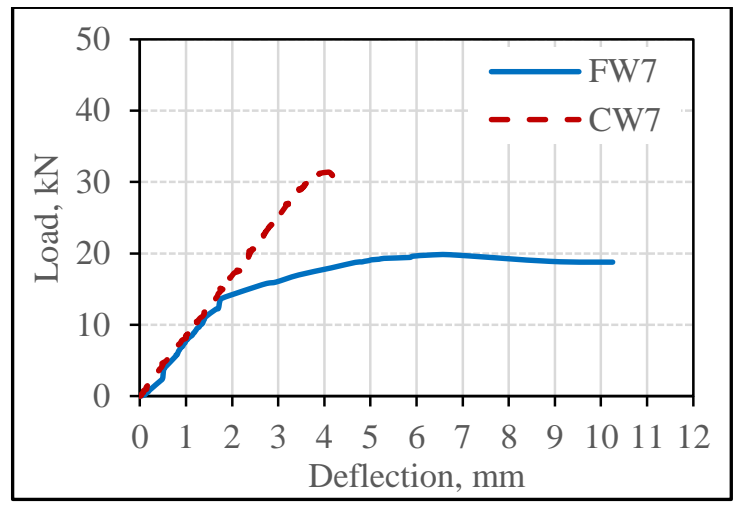

Figure 11: Comparison of Load-deflection between FW and CW girders
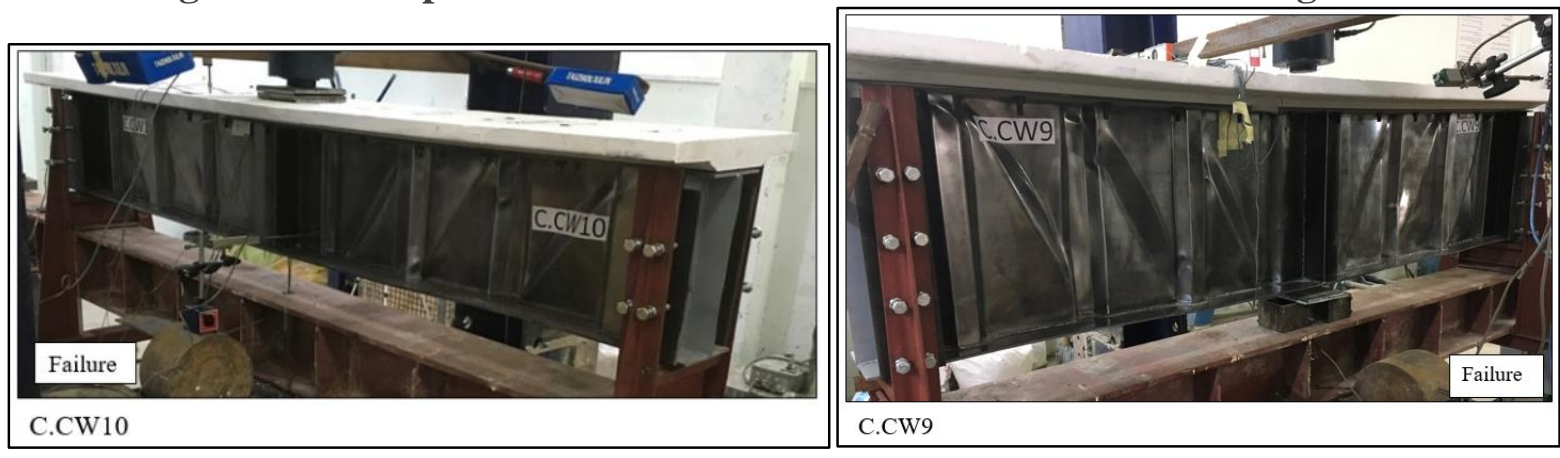

Figure 12: Failure Mode of Composite girders

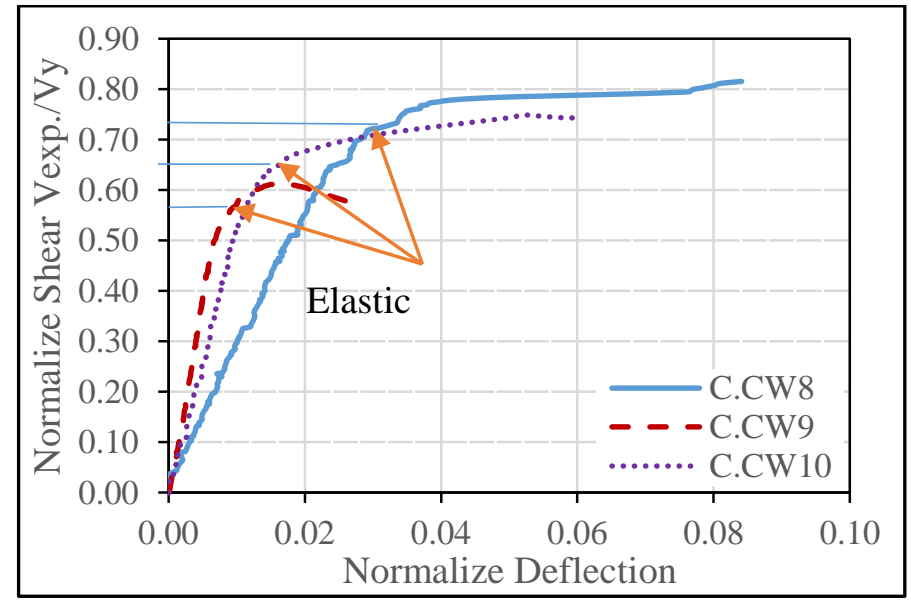

Figure 13:Shear-Relative Deflection of the Composite CW

Forgoing, the new corrugated technique and UHPC appeared an improvement of the girder's performance and increases web stability. However, the shear strength of the composite girder depends on the shear strength of the concrete and shear strength of the steel girder [16]. Therefore, Vasdravellis and Uy [23] proposed an equation for calculating the concrete contribution value to resist shear.

The comparison of the load-deflection curves of the composite girders between flat web girders and corrugated web girders were plotted in Figure 14. These curves showed that the new 


\section{$2^{\text {nd }}$ International Conference on Research in ENGINEERING}

and TECHNOLOGY

\section{5_27 September, 2020}

corrugated technique increased the elastic buckling load. The increments of the elastic buckling load (E.B.L.), are 44\%, 22\%, and 20\% between (C.CW8 and CFW8), (C.CW10 and C.FW10), and (C.CW9 and C.FW9) respectively. Therefore, the new pattern of corrugated with the UHPC deck slab was proposed in the present study is an active technique that increases the stability of the composite girders.

Also, the percentages of the increments of the elastic buckling load are $20 \%, 50 \%$, and $42 \%$ for corrugated web girders, as shown in Figure 15. That means the increment in Elastic buckling load capacity comes from the contribution of the deck slab of UHPC to resists the shear forces. In this circumstance, the deck slab increases the shear strength capacity for the composite girders, as revealed by Vasdravellis and Uy [23].
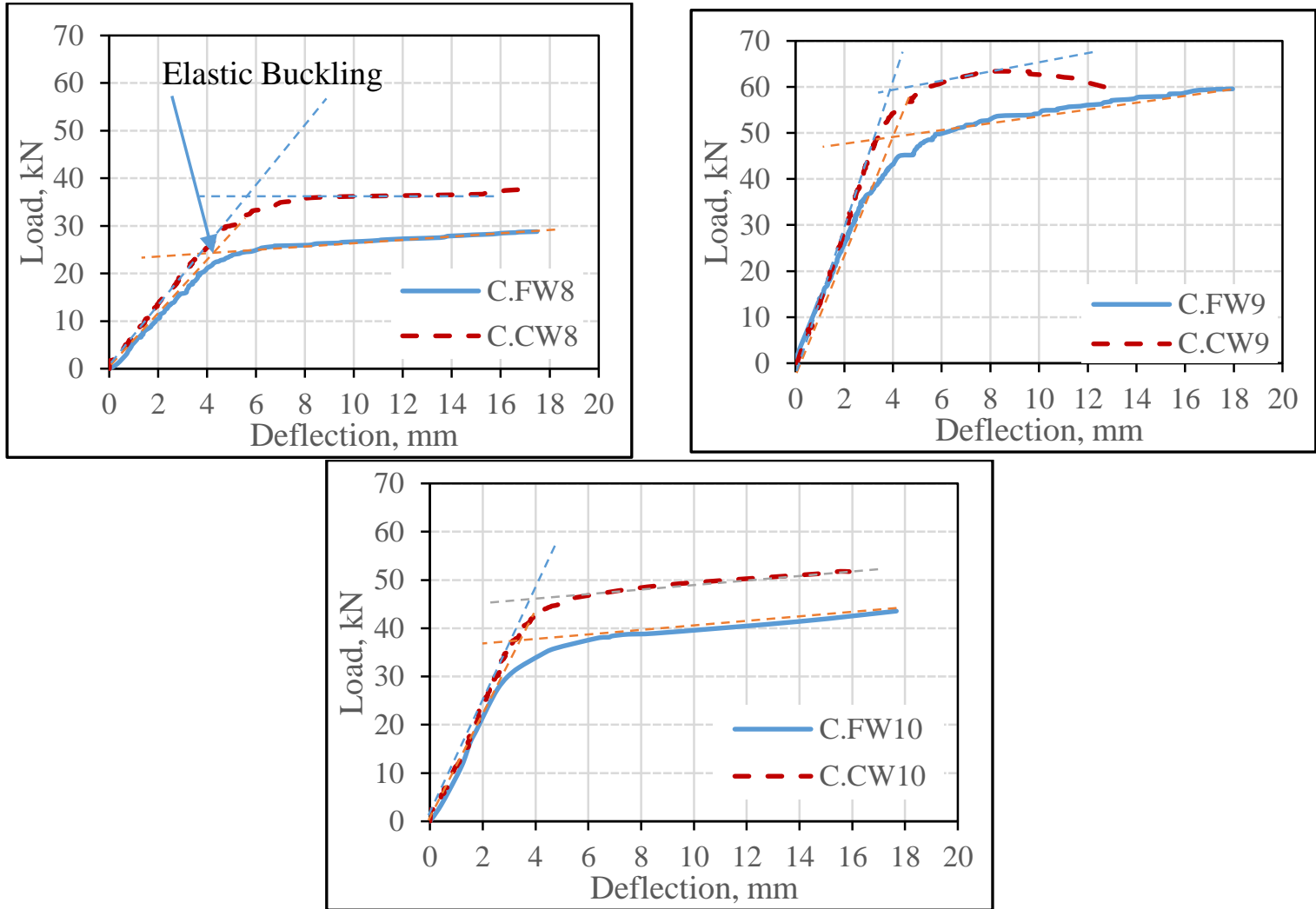

Figure 14: Comparison between corrugated and Flat web composite girders 


\section{$2^{\text {nd }}$ International Conference on Research in ENGINEERING}

and TECHNOLOGY

\section{5_27 September, 2020}

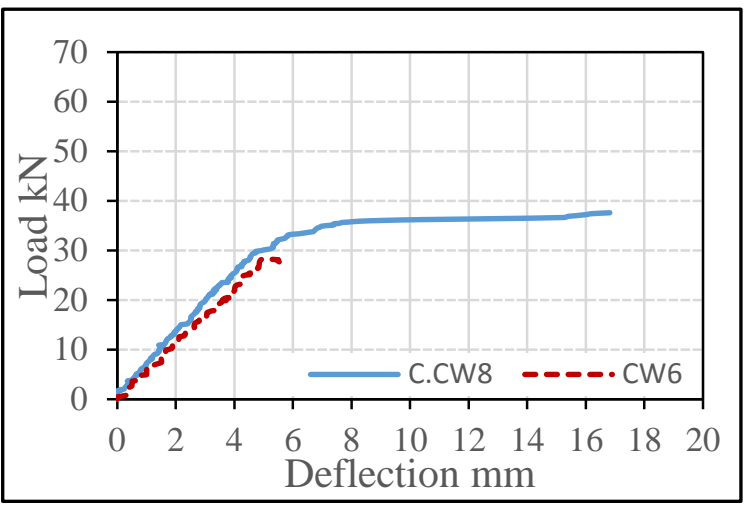

BERLIN, Germany

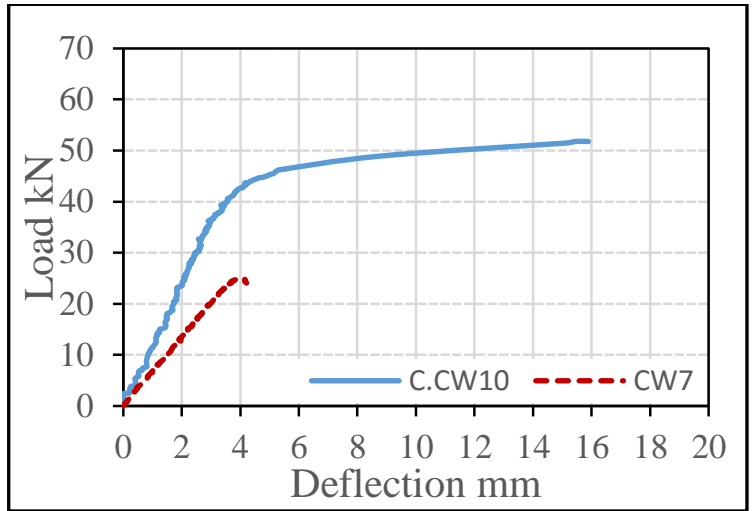

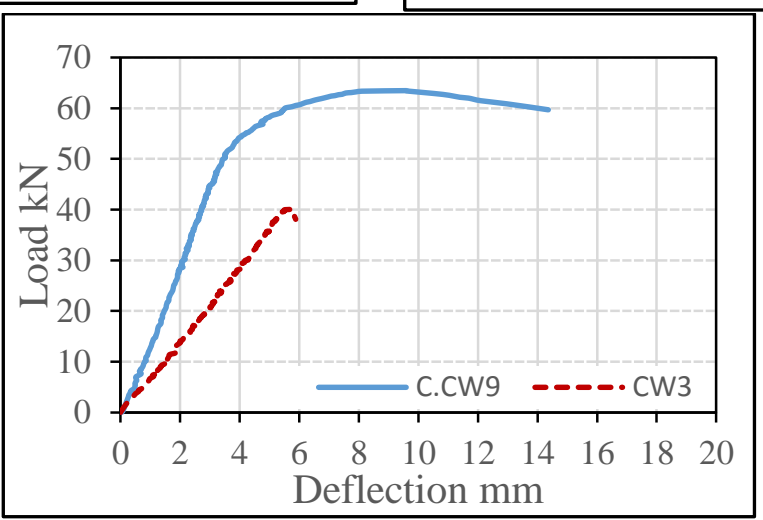

Figure 15: Comparison between composite and plate girders with the corrugated web

\subsection{Finite Element Modelling}

The present study adopted a 3D finite element analysis by the ABAQUS software program. The solid element was used for concrete deck slab, while the shell element was used for flanges, stiffeners, and the web. The analysis has been performed firstly by linear buckling and then by the Riks method.

The comparison between the test results and experimental results showed a good convergence. Also, the mode of failure coincided with the experimental test, as explained in Figure 16. 


\section{$2^{\text {nd }}$ International Conference on Research in ENGINEERING}

and TECHNOLOGY

\section{5_27 September, 2020}

\section{BERLIN, Germany}

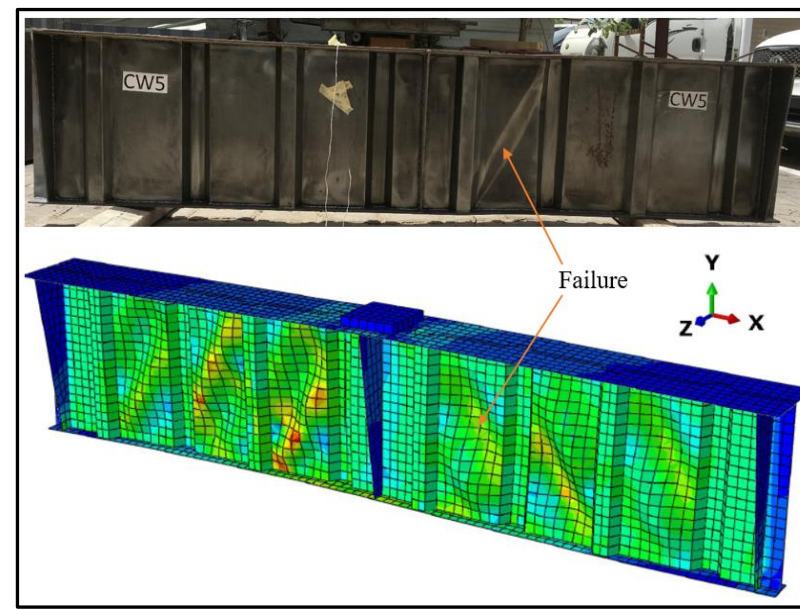

Plate girder CW5

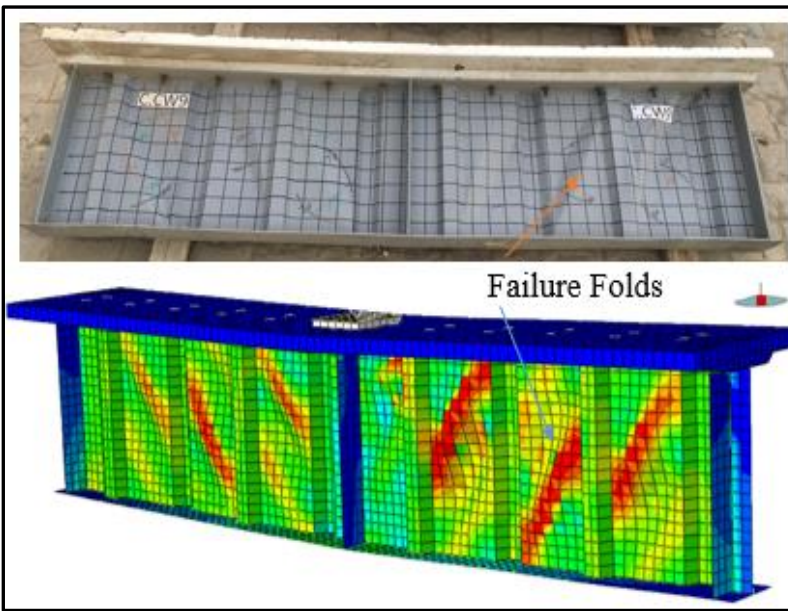

C.CW9

Figure 16: Testing and numerical Mode of failure of the plate and composite girders

\section{Conclusion and Discussion}

The reinforced web by corrugated technique is the aim of this study. Therefore, five corrugated web girders were tested with different parameters. Then a compression between the corrugated web and the flat web was conducted. The results of the test and comparison show the following; The plate girders formed of the corrugated web were failed due to interaction elastic buckling only because of the accordion shape prevent to improve the diagonal stress after elastic buckling.

In the present study proposed a modification to calculate the local, global, and interaction elastic buckling. The modification equation showed acceptable results when compared with testing results. The location of the neutral axis has no effect on the girder strength capacity because of the corrugated shape supported the flange vertically. Therefore, the slenderness of the compressive part has not affected. The girders with L/D ratio equaled 4.7 have a slender web, while increases the L/D ratio to 7.0 the web slenderness reduces; thereby, the shear strength increases. However, when the L/D ratio was equal to 10.5, that means the web sticky. Therefore, the shear stress becomes higher than the other.

The comparison between the flat web and corrugated web showed that the new technique of corrugated could be used to increases the stability of the web and then increases the girder strength capacity. The stiffness of the corrugated web girders is greater than flat web girders. However, the corrugated web did not prone to post-buckling effects after elastic buckling like flat web girders.

The results revealed that the load corresponded to elastic buckling increases when used with the new corrugated technique. The increased value depends on web slenderness. For the girders, C.FW8 and C.CW8, which have web slenderness equal to 167, increment percent of the CW than FW was 44\%. While for the girders C.FW10 and C.CW10, which have web slenderness equal to 250, increment percent was $22 \%$. Finally, the girders C.FW9 and C.CW9, Which have web slenderness equal to 375 , increment percent was $20 \%$. 


\section{$2^{\text {nd }}$ International Conference on Research in ENGINEERING}

and TECHNOLOGY

\section{5_27 September, 2020}

\section{References}

[1] “AISC 13th Steel_Construction_Manual COMPLETO.pdf.”.

[2] S. F. C. JACK c. McCormac, Structure Steel design, McCormic.pdf, Fifth Edit. Pearson Education.Inc., 2012.

[3] C. G. Salmon and J. E. Johnson, "2008

[Charles_G._Salmon,_John_E._Johnson,_Faris_A._Malh(BookZZ.org).pdf.” 1995.

[4] A. J. Daley, D. Brad Davis, and D. W. White, "Shear Strength of Unstiffened Steel ISection Members," J. Struct. Eng., vol. 143, no. 3, p. 04016190, Mar. 2016.

[5] M. M. Alinia, M. Shakiba, and H. R. Habashi, "Shear failure characteristics of steel plate girders," Thin-Walled Struct., vol. 47, no. 12, pp. 1498-1506, Dec. 2009.

[6] X. W. Chen, H. X. Yuan, X. X. Du, Y. Zhao, J. Ye, and L. Yang, "Shear buckling behavior of welded stainless steel plate girders with transverse stiffeners," Thin-Walled Struct., vol. 122, pp. 529-544, Jan. 2018.

[7] R. Sause, H. H. Abbas, W. G. Wassef, R. G. Driver, and M. Elgaaly, "Corrugated Web Girder Shape and Strength Criteria," ATLSS Reports. Pap. 245, no. 03, 2003.

[8] N. Subramanian, Design of Steel Structures by N. Subramanian-civilenggforall.pdf. 2008.

[9] M. Elgaaly, R. W. Hamilton, and A. Seshadri, "SHEAR STRENGTH OF BEAMS WITH CORRUGATED WEBS,” J. Struct. Eng. /, vol. 122, no. 4, pp. 390-398, 1996.

[10] J. H. Allan Bergfelt, "Bse-Cr-001_1968_8_132_D.Pdf," http://doi.org/10.5169/seals8784 Nutzungsbedingungen, 1968.

[11] M. Elgaaly, A. Seshadri, and R. W. Hamilton, "Bending Strength of Steel Beams with Corrugated Webs," J. Struct. Eng., vol. 123, no. 6, pp. 772-782, 2002.

[12] L. Cliffe and R. Luckham, Complex political emergencies, and the state: Failure and the fate of the state, Fourth Edi., vol. 20, no. 1. Chris Carson, 1999.

[13] M. N. Fardis, Ed., Innovative Materials, and Techniques in Concrete Construction. Dordrecht: Springer Netherlands, 2012.

[14] H. Gil, S. Lee, J. Lee, and H. Lee, "Shear Buckling Strength of Trapezoidally Corrugated Steel Webs for Bridges," Transp. Res. Rec. J. Transp. Res. Board, vol. 11s, pp. 473-480, Jan. 2015. 


\section{$2^{\text {nd }}$ International Conference on Research in ENGINEERING}

and TECHNOLOGY

\section{5_27 September, 2020} BERLIN, Germany

[15] K. Baskar and N. E. Shanmugam, "steel-concrete composite plate girders subject to combined shear and bending," J. Constr. Steel Res., vol. 59, no. 4, pp. 531-557, Apr. 2003.

[16] R. ALLISON, R. JOHNSON, and I. MAY, "Tension-Field Action in Composite Plate Girders.," Proceedings of the Institution of Civil Engineers, vol. 73, no. 2. pp. 255-276, 2007.

[17] T. M. Roberts and R. I. M. Al- Amery, "Shear Strength of Composite Plate Girders with Web Cutouts," ASCE, 2007.

[18] S. W. Yoo and J. F. Choo, "Evaluation of the flexural behavior of composite beam with inverted-T steel girder and steel fiber reinforced ultra-high performance concrete slab," Eng. Struct., vol. 118, pp. 1-15, Jul. 2016.

[19] E. Y. Sayed-Ahmed, "Design aspects of steel I-girders with corrugated steel webs," Electron. J. Struct. Eng., 2007.

[20] M. F. Hassanein and O. F. Kharoob, "Behavior of bridge girders with corrugated webs: (II) Shear strength and design," Eng. Struct., vol. 57, pp. 544-553, Dec. 2013.

[21] J. Easley, "Buckling Formulas for Corrugated Metal Shear Diaphragms," J. Struct. Div., vol. 101, no. ST7, pp. 1403-1417, 1975.

[22] J. Moon, J. Yi, B. H. Choi, and H. E. Lee, "Shear strength and design of trapezoidal corrugated steel webs,” J. Constr. Steel Res., vol. 65, no. 5, pp. 1198-1205, May 2009.

[23] G. Vasdravellis and B. Uy, "Shear Strength and Moment-Shear Interaction in SteelConcrete Composite Beams," J. Struct. Eng., vol. 140, no. 11, p. 04014084, Nov. 2014. 